\title{
An Evaluation of Parental Nutritional and Healthcare Awareness and Practices during Early Childhood in Karachi: An Insight from Mothers Belonging to Low-socioeconomic Class
}

\author{
Sameera Mian, Muhammad Yahya Noori, Asima Faisal
}

\section{ABSTRACT}

BACKGROUND: Health of mother and child is a major concern for Pakistan. Due to low literacy, poverty and lack of awareness, malnutrition is alarmingly common.

OBJECTIVE: The objective is to evaluate early childhood nutritional and healthcare practices in low socioeconomic class of Karachi.

METHODOLOGY: This survey based cross-sectional study was conducted at outpatient department of National Institute of Child Health $(\mathrm{NICH})$ from $15^{\text {th }}$ April to $31^{\text {st }}$ July 2015. Mothers $(\mathrm{n}=207)$ having children below 3 years of age were included in the study. Responses were tabulated and analyzed using SPSS and Open Epi software. Prior ethical approval was obtained from Institute of Business Management and from NICH.

RESULT: Data from 207 respondents showed that majority of mothers $81.2 \%(n=168)$ were without any formal schooling. Only $32.9 \%(n=68)$ children had appropriate weight for their age, while $83.6 \%(n=173)$ had some history of vaccination. Initiation of breastfeeding and weaning was found to be mostly at appropriate time. No association between gender and weight for age, and gender with vaccination status was found.

Chi-square test for association between education of parents and immunization showed significant association in both mother $(p=0.05)$ and father $(p=0.008)$.

CONCLUSION: The awareness regarding child health in mothers needs more improvement. Measures must be taken to broaden awareness as it will help in improving the healthcare status of mother and child both.

KEY WORDS: Childhood Nutrition, Mothers, Breast feeding, Weaning.

This article may be cited as: Mian S, Noori MY, Faisal A. An Evaluation of Parental Nutritional and Healthcare Awareness and Practices during Early Childhood in Karachi: An Insight from Mothers Belonging to Low-socioeconomic Class. J Liaquat Uni Med Health Sci. 2017;16(04):233-5. doi: 10.22442/jlumhs.171640540

\section{INTRODUCTION}

Effective nutritional practices are needed for healthy development and proper growth of children ${ }^{1,2}$, this helps in the generation of proper immunity and prevents morbidity and mortality due to communicable and non-communicable diseases ${ }^{1}$. A healthy and properly developed child is intellectually smart and is capable of becoming a useful citizen, thrives well and lives a happy and joyous life ${ }^{3}$. However, healthy development depends upon proper nutrition, especially at the early age. Properly administered nutrition prevents the child from diseases like marasmus, kwashiorkor, anemia, rickets and mental disabilities during the early development. Later in life, he is less prone to develop chronic infectious and non-infectious diseases ${ }^{4}$. Since physical strength and cognitive capability develops at the initial stages of life, children need a nurturing and educated family with stable structure, which would contribute towards their proper growth and development ${ }^{5}$. As parents are responsible in selecting the quantity, quality and frequency of food, they matter the most, when addressing the nutritional problems in children.

Pakistan has been reported to be affected heavily from nutritional problems as a significant proportion of children were found to be stunted in WHO reports ${ }^{6,7}$. Different communicable and non-communicable diseases, which could be prevented, are common with significant morbidity and mortality in Pakistani children. Though health literacy and sanitation is better in urban areas as compared to rural ones, the problem of malnutrition and poor growth and development is still very common ${ }^{7}$.

The objective of the study was to evaluate early childhood feeding patterns in the low socioeconomic households along with mothers understanding and perception about breast feeding practices. 


\section{METHODOLOGY}

A survey based cross-sectional study conducted on 207 mothers during $15^{\text {th }}$ April to $31^{\text {st }}$ July 2015 at the National Institute of Child Health OPD, Karachi. Ethical approval and permission was taken from the Health Management Department, College of Business Management, and Ethical Review Committee of $\mathrm{NICH}$. Lowa feeding Scale ${ }^{8-10}$, a close ended questionnaire used to collect data. Before administrating it was modified, validated and translated into local languages. Using $85 \%$ response distribution, 95\% Confidence level and $5 \%$ margin of error, a sample size of 195 was calculated with Raosoft $\circledast$ calculator. Systematic random sampling was used to select every second mothers attending healthcare facility with random start. Mothers aged $\geq 18$ years having children below 36 months of age were included in the study. Responses were analyzed using IBM SPSS (version $22)^{11}$ and Open Epi software ${ }^{12}$. A p-value of 0.05 was used as statistically significant.

\section{RESULTS}

Data from 207 mothers were collected. Most of the mothers were between 18 and 24 years of age $(51.2 \%, n=106)$, while $36.2 \%(n=75 \%)$ were between $25-31$ years, $12.6 \%(n=26)$ were above the age of 32 . More than two-thirds of the mothers had not received any formal schooling $(81.2 \%, n=168)$. Most of them $(61.4 \%, n=127)$ lived in extended family system. $54.1 \%(n=112)$ of fathers were also without any schooling. Most the families had monthly incomes of less than Rs. 20,000 (91.3\%, $n=199)$.

At the time of the visit $33.3 \%(n=69)$ children, for whom the mothers were seeking medical advice, were less than three months of age (Table I). Only $32.9 \%$ $(n=68)$ had the appropriate weight according to their age, $83.6 \%(n=173)$ had a history of immunization. The association between infant gender and whether the infant had weight appropriate for age was insignificant $(p=0.185)$. Chi-Square test for the association of mother's education and immunization showed significant $(p=0.05)$ association between the two variables. Educational status of fathers and immunization status of the child also had significant association $(p=0.008)$. No association between gender and weight for age, and gender with vaccination status was found.

Most of the mothers started breastfeeding within the first hour after birth $(86.9 \%, n=180) .97 .6 \%(n=202)$ of mothers considered breastfeeding to be an ideal approach, while $80 \%(n=167)$ considered it to be more convenient as compared to formula feeding. The motivation mostly came from the mothers themselves $(34.3 \%, n=71)$, while a considerable number was motivated by healthcare professionals at the antenatal clinics or elsewhere $(30 \%, n=62)$. Among children more than six months of age $(n=176)$, half had their weaning started at the age of $4-6$ months $(n=85$, $48.29 \%$ ).

TABLE I:

AGE OF BABIES, FOR WHOM THE MOTHERS WERE VISITING HEALTHCARE FACILITY

\begin{tabular}{|c|r|r|}
\hline Age (Months) & \multicolumn{1}{|c|}{$\mathbf{N}$} & \multicolumn{1}{|c|}{$\%$} \\
\hline$<3$ & 8 & 3.9 \\
\hline $3-6$ & 17 & 8.2 \\
\hline $7-12$ & 69 & 33.3 \\
\hline $13-18$ & 38 & 18.4 \\
\hline $19-24$ & 38 & 18.4 \\
\hline $25-30$ & 15 & 7.2 \\
\hline $31-36$ & 22 & 10.6 \\
\hline Total & $\mathbf{2 0 7}$ & $\mathbf{1 0 0}$ \\
\hline
\end{tabular}

\section{DISCUSSION}

Our results showed that majority of the parents were without formal schooling. More than two thirds of the children, who were brought to the healthcare facility, had weight that was below the appropriate standard weight for their age and were lower than the $50^{\text {th }}$ Percentile weight-for-age as per World Health Organization. These findings appropriately reflect the sad state of affairs in the country and highlight the dire need of directing our attention towards malnutrition as under-five mortality rate is among the highest in the region (8.1\% in 2015), close to the developing African Countries ${ }^{6,13}$. There was a significant association between the educational status of parents and the status of immunization of their children of both mother $(p=0.05)$ and father $(p=0.008)$. This highlights the importance of literacy and health literacy in particular, which has generally been reported to be low in our population ${ }^{14}$.

Breastfeeding and weaning practices of the mothers mostly seemed satisfactory, and most of the mothers were observed to be practicing breast-feeding along with properly introduced weaning. A recent study from Karachi however, shows that a significant majority of working mothers, adopt bottle-feed for their children ${ }^{15}$. The result of the current study showed that the motivation for breast-feeding was mainly from the healthcare providers, which was a good sign and contrary to the common belief that efforts of health professional and awareness program does not plays any role in this regard. Since these practices have a very important role in proper childhood development, it 
is important that promotional and awareness programs should be further strengthened to increase awareness among the mothers.

The results showed that only $83.6 \%$ children had received some sort of vaccination, which is another alarming situation, because a higher proportion of vaccination coverage is expected in urban areas. However this was higher than the reported urban statistics of $66 \%$ and immunization statistics of Sindh $(29 \%)$ as per the data from Pakistan Health and Demographic Survey of $2012-2013^{7}$. It is important to expand the immunization coverage and parents understanding regarding immunization. Adapting General practitioners based systems for immunization updates can be of significant help in this regard.

\section{CONCLUSION}

The level of health care awareness needs improvement, especially regarding immunization and nutritional needs of the children. Measures must be taken to broaden awareness as it will help in improving the healthcare status of moths and child both.

\section{REFERENCES}

1. Sima P, Vetvicka V, Vannucci L. Co-Evolution of Nutrition and Immunity. J Food Sci Nutr. 2016; 2: 008. DOI: 10.24966/FSN-1076/100008

2. Vickers $\mathrm{MH}$. Early life nutrition, epigenetics and programming of later life disease. Nutrients. 2014; 6(6):2165-78. Doi: 10.3390/nu6062165.

3. Prado EL, Dewey KG. Nutrition and brain development in early life. Nutr Rev. 2014; 72 (4):267-84. doi: 10.1111/nure.12102

4. Langley-Evans SC. Nutrition in early life and the programming of adult disease: a review. J Hum Nutr Diet. 2015; 28 Suppl 1:1-14. doi: 10.1111/ jhn.12212.

5. Vollmer S, Bommer C, Krishna A, Harttgen K, Subramanian SV. The association of parental education with childhood under nutrition in low-and middle-income countries: comparing the role of paternal and maternal education. Int $\mathrm{J}$ Epidemiol. 2017; 46(1):312-23. doi: 10.1093/ije/ dyw133.

6. UN Children's Fund (UNICEF), Levels \& Trends in Child Mortality, September 2015, available at: http://www.refworld.org/docid/55f6c3304.html.

7. National Institute of Population Studies (NIPS) [Pakistan] and ICF International. 2013. Pakistan Demographic and Health Survey 2012-13. Islamabad, Pakistan, and Calverton, Maryland, USA: NIPS and ICF International.

8. Motee A, Ramasawmy $D$, Pugo-Gunsam $P$, Jeewon R. An Assessment of the Breastfeeding Practices and Infant Feeding Pattern among Mothers in Mauritius. J Nutr Metab. 2013; 2013:243852. doi: 10.1155/2013/243852

9. de la Mora A, Russell DW, Dungy $\mathrm{Cl}$, Losch M, Dusdieker L. The lowa infant feeding attitude scale: analysis of reliability and validity. J Appl Soc Psychol. 1999; 29(11):2362-80. doi: 10.1111/ j.1559-1816.1999.tb00115.x

10. Saied H, Mohamed A, Suliman A, Anazi WA. Breastfeeding knowledge, attitude and barriers among Saudi women in Riyadh. JNSR. 2013; 3 (12):6-13.

11. IBM Corp. Released 2013. IBM SPSS Statistics for Windows, Version 22.0. Armonk, NY: IBM Corp.

12. Dean AG, Sullivan KM, Soe MM. OpenEpi: Open Source Epidemiologic Statistics for Public Health, Version. www.OpenEpi.com, updated 2013/04/06.

13. Yang Z, Huffman SL. Nutrition in pregnancy and early childhood and associations with obesity in developing countries. Matern Child Nutr. 2013; 9 (S1):105-19. doi: 10.1111/mcn.12010.

14. Noori MY, Kazi M, Shahid A, Faisal A. The Relationship of Health Literacy, Perceived Health Information Need and Preventive Health Related Behavior in Urban Karachi. JIIMC. 2015; 10 (3):210-13.

15. Khaliq A, Qamar M, Hussaini SA, Azam K, Zehra $N$, Hussain $M$, et al. Assessment of knowledge and practices about breastfeeding and weaning among working and non-working mothers. J Pak Med Assoc. 2017; 67(3):332-38.

\begin{tabular}{|ll}
\hline AUTHOR AFFILIATION: & Dr. Muhammad Yahya Noori \\
Sameera Mian & (Corresponding Author) \\
Student, MBA & Assistant Professor of Pathology \\
Health and Hospital Management & Dow International Medical College \\
Institute of Business Management & Dow University of Health Sciences \\
Karachi, Sindh-Pakistan. & Karachi, Sindh-Pakistan. \\
& Email: yahyanoori@gmail.com
\end{tabular}

Asima Faisal

Department of Health Management College of Business Management Institute of Business Management, Karachi, Sindh-Pakistan. 